\title{
The Relational and Representational Character of Perceptual Experience
}

\section{Susanna Schellenberg}

The history of philosophy is a history of false dichotomies. The dichotomy between relationalists and representationalists is one such false dichotomy. Relationalists argue that perception is fundamentally a matter of a perceiver being related to her environment. Representationalists argue that perception is fundamentally a matter of a perceiver representing her environment. However, the standard views in the debate are either austerely relationalist or austerely representationalist. According to austere representationalists, perception is fundamentally representational but not fundamentally relational. According to austere relationalists, perception is fundamentally relational but not fundamentally representational. ${ }^{1}$ Against both, I argue that perceptual relations to the environment and the content of experience should be recognized to be mutually dependent in any explanation of what brings about perceptual awareness of the environment.

Another way of expressing the idea is that being acquainted with particulars in one's environment is neither metaphysically nor explanatorily more basic

I am grateful to Bill Brewer, Todd Ganson, and an anonymous referee for Oxford University Press for detailed written comments. An early version of this paper was presented at CUNY and the University of Miami. Thanks also for many helpful discussions at those occasions.

${ }^{1}$ For austere representationalist views, see McGinn (1982), Davies (1992), Tye (1995), Lycan (1996), and Byrne (2001) among many others. For austere relationalist views, see Campbell (2002), Travis (2004), Johnston (2004, 2006), Brewer (2006), Fish (2009), Genone (forthcoming), and Raleigh (forthcoming) among others. Martin (2002a, 2004) argues against any view on which experience can be analyzed in terms of a propositional attitude and a content, leaving open the possibility that experience could have content without the subject standing in a propositional attitude to that content. Since he does not outright deny that experience has content, I will discuss his view only to the extent that his positive view of perceptual experience is structurally similar to that of austere relationalists. Campbell (2002) calls his view the "relational view," Martin (2002a, 2004) calls his "naïve realism," while Brewer (2006) calls his the "object view." I will refer to the view with the label "austere relationalism" since the most distinctive features of the view are arguably the central role of relations between perceiving subjects and the world as well as its austerity: the view is austere insofar as it denies that experience has any representational component. There is room in logical space to reject representationalism without endorsing a relationalist view. For such a view, see Gupta (2012) 
than representing one's environment. As I argue, there is no such thing as being brutally acquainted with one's environment. In being perceptually related to one's environment one employs perceptual capacities that yield representational states. So in contrast to austere relationalists, I argue that perceptual relations to particulars neither ground nor explain perceptual representations. In contrast, to austere representationalists I argue that perceptual representations neither ground not explain perceptual relations to particulars in the environment. Perceptual relations and representations are mutually dependent.

In my (2010 and 2011), I have argued for the view that perceptual experience is fundamentally both relational and representational. Brewer, one of the main proponents of austere relationalism, has recently responded to my argument (see his 2011, pp. 64-65). His response gets to the heart of the issues at stake in the debate on whether experience has content. Therefore, it will serve as the foil for the present discussion. In order to adequately respond to his argument, I will clarify first what is at stake in the debate on whether experience has content by discussing the idea that experience is a matter of representing (8.1) and the idea that experience is a matter of being related to one's environment (8.2). I will then recapitulate my (2011) argument for the thesis that experience is fundamentally relational and representational (8.3). Finally, I will respond to Brewer's reply to my argument (8.4).

\subsection{Perception and Representation}

Let the Content Thesis be the thesis that perceptual experience is fundamentally a matter of representing the environment as being a certain way.

Content Thesis: Perceptual experience is fundamentally a matter of representing the environment as being a certain way.

As austere relationalists point out, this thesis is rarely argued for. While many views have been defended that endorse it, more often than not such views simply assume that experience is representational and proceed to argue for one particular way of understanding its content. Following Campbell (2002), I use the label "the representational view" or "representationalism" for any view that endorses the Content Thesis.

There are three critical choice points for any representationalist view of perceptual experience. One choice point is how to understand the relationship between the experiencing subject and the content of her experience. In order to

It is important to distinguish this view from the more specific view according to which the sensory character of experience supervenes on or is identified with its content. Such views are sometimes labeled "representationalism" rather than the more traditional "intentionalism." I will reserve "representationalism" for any view that endorses the Content Thesis. "Representationalism," so understood, is neutral on the relationship between content and sensory character. avoid terminological confusions, this choice point is critical in the discussion of whether experience has content. Therefore, I will address the different options in some detail. ${ }^{3}$ The Content Thesis must be distinguished from a thesis on which the relation between the experiencing subject and the content of her experience is one of mere association. I call this the Association Thesis.

Association Thesis: Every experience can be associated with (propositional) content in the sense that sentences can be articulated that describe how the environment seems to the subject, without the content expressed being a proper part of the experience.

Any account of experience can accept the Association Thesis. After all, any account of experience can accept the fact that an experience can be (at least partially) described. But this fact does not entail that the experience has the content that is expressed with the description. Certainly, it does not entail that perceptual experience is fundamentally a matter of representing the environment as being a certain way. So the Association Thesis does not entail the Content Thesis. To show why, consider a painting. A painting can be described, but it does not follow from this that the painting has the content that is expressed with the description. ${ }^{4}$ Similarly, while describing what a subject experiences is informative, the fact that an experience can be described does not entail that the relevant experience has the content expressed with the description. ${ }^{5}$

The Content Thesis posits that the content of experience is an aspect of experience proper and not merely associated with the experience. So the Content Thesis differs from the Association Thesis in kind. After all, if experience is fundamentally a matter of representing the environment in a certain way, then experience will have content that is not merely associated with the experience. It will have content that is a proper part of the experience. The relevant notion of "fundamentality" in the Content Thesis marks a denial of the idea that content is merely associated with experience rather than being a proper part of experience.

Now, a controversial version of the Content Thesis has it that the relationship between the experiencing subject and the content of her experience is that of a propositional attitude: the experiencing subject stands in a propositional attitude to the content of her experience. This Propositional Attitude Thesis posits both that the content of experience is a proposition and that experience is a matter of standing in a certain attitudinal relation to this proposition, analogous

${ }^{3}$ As I have argued elsewhere (see my 2011), some accounts of perceptual content fall prey to the austere relationalist objections; others (in particular the view I defend which acknowledges mutual dependence of the relational and representational character of perceptual experience) arguably do not.

${ }^{4}$ For a detailed discussion of the relation between the content of pictures and the content of experiences and mental states more generally, see Crane (2009).

${ }^{5}$ Byrne (2009) and Siegel (2010) have presented arguments in support of the view that experience has content, but arguably their arguments do not establish more than the Association Thesis. 
to the sense in which one might say that belief is a matter of standing in the believing relation to the content of the belief. English does not have a word to denote such a perceptual attitudinal relation. Byrne (2009, p. 437) calls the relation the ex-ing relation; Pautz (2010, p. 54) calls it the sensorily entertaining relation; Siegel (2010, p. 22) calls it the A-relation. The Propositional Attitude Thesis is a version of the Content Thesis. However, it is important to keep in mind that we can accept the Content Thesis without accepting the Propositional Attitude Thesis: The Content Thesis is committed neither to the content of experience being a proposition nor to the experiencing subject standing in a propositional attitude to the content of her experience.

An even more controversial version of the Content Thesis has it that the relation between the experiencing subject and the content of her experience is an awareness relation: The experiencing subject stands in an awareness relation to the content or its constituents, such that this awareness relation grounds the sensory character of the experience. This Awareness Thesis can be traced back to Russell (1913), who argued that an experiencing subject stands in acquaintance relations to particulars that in turn can be understood as the constituents of the proposition that characterizes her experience. ${ }^{6}$ In the tradition of Russell, some representationalist views are formulated in a way that suggests a commitment to the Awareness Thesis. While the Awareness Thesis entails the Content Thesis, the converse is not the case: we can accept the Content Thesis without accepting that perceivers stand in any kind of awareness relation to the content of their experience. Experience can be understood to have content in that the experiencing subject represents her environment by employing perceptual capacities without the subject standing in an awareness relation to the content yielded by employing those capacities.

The Awareness Thesis and the Propositional Attitude Thesis carry controversial commitments that the Content Thesis does not entail. As I will show, we can accept that perceptual experience is fundamentally a matter of representing one's environment without being committed to these more contentious theses. The Content Thesis is neither committed to the thesis that the content of experience is a proposition, nor is it committed to the thesis that the experiencing subject stands in an awareness relation to the content of her experience. This is important since at least some arguments against the Content Thesis assume that this thesis entails those more controversial theses. ${ }^{7}$ Such arguments lose their grip, if one recognizes that the Content Thesis does not carry the commitments of the more controversial theses.

So far, we have distinguished different ways of understanding the relation between the experiencing subject and the content of her experience. A second

${ }^{6}$ One could argue however that on Russell's view, acquaintance with particulars and universals is more basic than any contentful mental state in that acquaintance with particulars and universals explains how it is possible to entertain the relevant contents. Thanks to Bill Brewer for pressing me on this point.

${ }^{7}$ See, for example, Travis (2004). choice point one faces is how to understand the relationship between the content and the sensory character of perceptual experience. One might identify content and sensory character. Alternatively, one might deny identity but maintain either that content is grounded in sensory character or that sensory character is grounded in content. Or, one might treat content and sensory character as independent elements of experience, thereby denying that there is any identity or grounding relation between content and sensory character.

A third choice point is how to understand the nature of perceptual content. This choice point contains several levels. One is whether the content is understood in terms of a Russellian proposition, a possible world proposition, a Fregean sense, or in some other way. A second is whether perceptual content is conceptually or nonconceptually structured. ${ }^{8} \mathrm{~A}$ third is whether or not the content of experience is propositionally structured. A fourth is whether the content is (at least in part) externally individuated and so dependent on the experiencer's environment, or alternatively only internally individuated and so independent of the experiencer's environment.

I will consider the final point in more detail, since the question of whether perceptual content is environment-dependent is crucial in the debate on whether experience is fundamentally representational, relational, or fundamentally both relational and representational. 9 According to austere representationalism, the content of experience is internally individuated in the sense that it is independent of the environment of the experiencing subject. ${ }^{10}$ The view is austere since it leaves no significant room for a relational component. The only difference between subjectively indistinguishable experiences in distinct environments is a difference in the causal relation between the experiencing subject and her environment. According to austere representationalists, this difference in causal relation has repercussions neither for the content of the experiences nor for their sensory character. On such a view, the content of experience can be analyzed in terms of existentially quantified content of the form that there is an object $x$ that instantiates a certain property $F:(\exists x) F x$. So experience represents only that there is an object with the relevant properties in the external world. No element of the content depends on whether there is in fact such an object present. Austere representationalism has it that the content lays down a condition that something must

8 The debate on whether perceptual content is conceptually or nonconceptually structured is sometimes understood as a debate about whether perceptual content is structured by Fregean concepts and not just properties and objects. On this understanding, the first and second level distinguished above collapses. However, there are ways to understand perceptual content as structured by modes of presentation without committing oneself to the idea that the content is thereby conceptually structured (see, for example, Schellenberg 2013). Therefore, I distinguish the two debates. Thanks to Todd Ganson for pressing me on this point.

${ }^{9}$ Nanay (forthcoming) argues that the debate between representationalists and relationalists is best understood as a debate not about what is fundamental in an account of perceptual experience but rather as a debate about the individuation of perceptual states.

${ }^{10}$ McGinn (1982), Davies (1992), Tye (1995), Lycan (1996), and Byrne (2001) among others have defended views that are committed to perceptual content being independent of the experiencer's environment. 
satisfy to be the object determined by the content. The condition to be satisfied does not depend on the object that satisfies it. So the relation between content and object is simply the semantic relation of satisfaction. Of course, the object of the experience does not fall out of the picture altogether on an austere representationalist view. The content of the experience is accurate only if there is an object at the relevant location that instantiates the properties specified by the content. But the important point is that whether an object of the right kind is present has a bearing only on the accuracy of the content, not on the content itself.

We can contrast such a non-relational view with a relational view of perceptual content, that is, a view on which perceptual content is understood to be inherently relational and so at least in part environment-dependent. For something to be the object of a relational content, the content must constitutively depend at least in part on that very object. So while a non-relational content is the very same regardless of the situation in which the subject experiences, a relational content differ depending on what environmental particular (if any) the subject is related to. The token relational content co-varies with the environment of the experiencing subject. In the case of a successful perceptual experience, the token content determines a referent. Insofar as the token relational content is individuated in part by the environmental particulars perceived, it is at least in part environment-dependent.

\subsection{Perception and Relations}

Austere relationalists have formulated at least six different objections to the Content Thesis. They can be stated as follows:

The Particularity Objection: Representationalist views cannot adequately account for the fact that we see particulars and have perceptual knowledge of particulars (e.g., Campbell 2002; Martin 2002b).

The Indeterminacy Objection: If perception has representational content, then the way an object looks on a given occasion must fix what representational content the perception has. However, the way an object looks on a given occasion does not fix what representational content the perception has. Therefore, perception does not have representational content (e.g., Travis 2004).

The Accuracy Condition Objection: Perception is a relation between a perceiving subject and her environment or alternatively an event in which such a relation obtains. Relations and events do not have accuracy conditions. So perception is not the kind of thing that can be accurate or inaccurate. If accounting for accuracy conditions is the reason for introducing content, then denying that experience has accuracy conditions undermines at least this reason for the Content Thesis (e.g., Brewer 2006).
The Phenomenological Objection: Representationalist views misconstrue the phenomenological basis of perceptual experience insofar as they detach the sensory character of experience from relations to qualitative features of the environment (e.g., Campbell 2002; Martin 2002a; Brewer 2007).

The Epistemological Objection: Representationalist views do not properly account for the epistemological role of perceptual experience. Only if perceptual experience is itself not representational can it constitute the evidential basis for demonstrative thoughts and ultimately perceptual knowledge (e.g., Campbell 2002).

The Grounding Objection: Representationalist views cannot adequately account for the fact that perceptual relations to the environment provide the ground for the possibility of thought and language (e.g., Campbell 2002; Brewer 2006).

I have shown elsewhere that a representationalist view on which perceptual content is understood to be inherently relational does not fall prey to these objections and will not rehearse those arguments here (see my 2010, 2011). I will proceed immediately to stating the relationalist view that has been formulated in response to these objections.

The central positive idea of relationalism is that perceptual experience is not fundamentally a matter of representing, but rather fundamentally a matter of a subject standing in a perceptual relation to a material, mind-independent object, a property that this object instantiates, an event, or a combination thereof (Campbell 2002; Brewer 2006). Alternatively, experience is thought of as an event in which such a relation obtains (Martin 2002a). Views differ further on whether subjects are perceptually related only to objects in an environment (Brewer 2006, 2011) or whether they are related also to the properties that these objects instantiate (Campbell 2002). Views differ moreover on how the perceptual relation is understood: It can be understood as a causal relation, a sensory relation such as an awareness relation, or as an epistemic relation such as an acquaintance relation. Finally, views differ on how they oppose representationalism: While all austere relationalists agree that no appeal to content is necessary to give a good account of perceptual experience, some go a step further in arguing that representationalism is less attractive than relationalism in explaining certain phenomena, or indeed that representationalism cannot explain certain phenomena (e.g., Brewer 2006, 2011).

What austere relationalist views have in common is that they endorse the negative thesis that no appeal to representational content is necessary in a philosophical account of perceptual experience, in conjunction with the positive thesis that any perception essentially involves at least three components: a subject, the environment of the subject, and a perceptual relation between the subject and certain elements of her environment.

For the sake of definiteness, I will work with the case of a subject being perceptually related to a mind-independent object that instantiates a perceivable property. 
Everything I will say about this case needs to be modified only slightly to fit with other versions of austere relationalism. Given this case, the austere relationalist thesis can be articulated in the following way: A subject perceives a particular white cup only if she is perceptually related to that particular white cup; no appeal to content is necessary to fully explain the nature of the subject's perceptual experience. Being perceptually related to a white cup may in turn be analyzed in terms of being perceptually related to a cup instantiating whiteness, where the relevant object and property-instance are collocated. More generally, subject $S$ perceives object $o$ as instantiating property $F$ only if $S$ is perceptually related to $o$ and an instance of $F$, where $o$ and the instance of $F$ are collocated.

It will be helpful to make three clarifications about the view at stake. First, austere relationalists do not deny that beliefs and judgments are formed on the basis of perception. So what is contentious is not whether perception brings about mental states with content. The questions at stake are rather whether this content is an aspect of perception proper and whether the thesis that experience is representational is fundamental in an account of perceptual experience. Second, austere relationalists do not contest that perception involves cognitive or neural processing that can be characterized in terms of representations (Campbell 2002, 2010), but insist rather that no appeal to content is necessary to explain the nature of the awareness of our surroundings that we have as a consequence of this cognitive processing. So while for example Campbell allows that representations play a role on a subpersonal level, he denies that any appeal to representations is necessary to explain perception on a personal level. Finally, austere relationalists need not deny that we can articulate propositions to express what we experience. Acknowledging that a subject can articulate such propositions entails no commitment to positing that her experience itself has the content articulated. It might just be that the propositions articulated are merely associated with the experience. Austere relationalists can accept the Association Thesis. So in order to establish the Content Thesis, we cannot simply appeal to the fact that we can articulate propositions to express what we experience. Appealing to such a fact would merely establish the Association Thesis. We need to show that these propositions or contents are a proper aspect of experience and indeed that they are a fundamental aspect of experience.

\subsection{Perceptual Content Defended Again}

I will present my argument for the Content Thesis in two stages. I will first put forward the Master Argument for perceptual content. The Master Argument is

${ }^{11}$ For an argument that disposing of perceptual representations is inconsistent with empirical findings about dorsal perception and about the multimodality of perception, see Nanay (this volume). For a discussion of how the ventral and the dorsal stream work together in visual experience, see also Wu (forthcoming). For a critical discussion of recent representationalist views on empirical grounds, see Bronner, Kerr, and Ganson (forthcoming). compatible with accepting only the Association Thesis, and so is not sufficient for establishing the Content Thesis. However, we will need it to establish that thesis, since it clarifies the relevant notion of content. In the next section, I will put forward the Argument for Relational Content, which builds on the notion of content established by the Master Argument. By arguing that perception is fundamentally a matter of representing one's environment, I will be in a position to conclude the Content Thesis. By arguing that perceptual content is best understood to be inherently relational, I will be in a position to conclude that perceptual experience is fundamentally both relational and representational.

\subsubsection{THE MASTER ARGUMENT FOR PERCEPTUAL CONTENT}

The mere fact that the environment sensorily seems a certain way when one perceives supports a standard notion of perceptual content. The Master Argument for perceptual content goes as follows:

P1: If a subject is perceptually related to her environment (while not suffering from blindsight or any other form of unconscious perception), then she is sensorily aware of her environment.

P2: If a subject is sensorily aware of her environment, then her environment sensorily seems a certain way to her.

P3: If her environment sensorily seems a certain way to her, then she has an experience with content $C$, where $C$ corresponds to the way her environment sensorily seems to her.

Conclusion 1: If a subject is perceptually related to her environment (while not suffering from blindsight or any other form of unconscious perception), then she has an experience with content $C$, where $C$ corresponds to the way her environment sensorily seems to her.

P4: Her environment is either the way it sensorily seems to her or it is different from the way it sensorily seems to her.

P5: If a subject has an experience with content $C$, then $C$ is either accurate (if her environment is the way it sensorily seems to her) or inaccurate (if her environment is not the way it sensorily seems to her).

Conclusion 2: If a subject is perceptually related to her environment (while not suffering from blindsight or any other form of unconscious perception), then the content of her experience is either accurate or inaccurate. ${ }^{12}$

${ }^{12}$ While in my (2011) I formulate this argument in terms of "aware" and "seems," I here speak of "sensorily aware" and "sensorily seems." This clarifies the relevant notion of "aware" and "seems." Furthermore, while in my (2011) I formulate this argument by saying that the subject is perceptually related to the world, I here formulate the same argument by saying that the subject is perceptually related to her environment. This clarifies which part of the world the subject is perceptually related to. Brewer's response to my argument is in no way affected by these two clarifications. 
Brewer accepts the first two premises of the argument. It is not contentious that if we are perceptually related to our environment, then we will be sensorily aware of that environment $\left(P_{1}\right)$. Moreover, it is not contentious that if we are sensorily aware of our environment, then our environment will sensorily seem a certain way to us $\left(P_{2}\right)$.

We can moreover recognize $P_{3}$ to be true, if we recognize that there is a notion of content on which the content of experience corresponds to the way the environment sensorily seems to the experiencing subject. Let's call this connection between content and the way the environment seems the seems-content link. Since we are talking only of sensory seemings the relevant cases are constrained to those in which a subject is hearing, seeing, smelling, touching, or experiencing the environment in some other sensory mode, or a combination of sensory modes. If we recognize the seems-content link, then the idea that the environment can seem a certain way to a subject without her being in a contentful mental state becomes impossible. But the idea that the environment can seem a certain way to a subject without her being in a contentful mental state is precisely the idea that austere relationalism relies on.

Recognizing the seems-content link is compatible with accepting that any given scene can be perceived in many different ways. The way the environment seems to the perceiver may change from moment to moment even as her gaze remains steady. Say she is looking at a pig. She can direct her attention at its shape, its color, the texture of its skin, or any combination of these features. As her attention shifts, her sensory character will change. One or more propositions can be associated with every one of these phenomenal states and thus with every one of these ways that the environment may seem to her. All of these propositions or sets of propositions are equally legitimate contents of possible experiences she may enjoy while beholding the pig. Nevertheless, at any given moment the environment will seem to her to be one single way. This is all that we need to establish the seems-content link. ${ }^{13}$

Once one has recognized the seems-content link, only minor further commitments are necessary to establish that the way the environment seems to an experiencing subject is assessable for accuracy. In virtue of a subject perceiving the environment, it seems a certain way to her. The way the environment seems to a subject determines the way the environment would have to be for the content of her experience to be accurate. The environment is either the way it seems to her or it is different from the way it seems to her $\left(P_{4}\right)$. If the environment is the way it seems to her, then the content of the experience is accurate. In all other cases, the content of the very same experience is inaccurate. So if a subject has an experience

${ }^{13}$ For a detailed discussion of how these premises must be interpreted depending on whether one understands the seemings in question comparatively or noncomparatively, see my (2011). For present purposes we can ignore this detail, since the Master Argument can be accepted regardless of whether seemings are understood comparatively or noncomparatively. For the distinction between the comparative and noncomparative use of appearance words, see Chisholm (1957, pp. 50-53) and Jackson (1977, pp. 30ff.). with a particular content, then this content is either accurate or inaccurate $\left(P_{5}\right)$. It follows from this, together with $P_{1}$ and $P_{2}$ of the Master Argument, that if a subject is perceptually related to the environment, then the way the environment seems to her is assessable for accuracy. Together with $P_{3}$, it follows that if a subject is perceptually related to the environment, then the content of her experience is either accurate or inaccurate. ${ }^{14}$

\subsubsection{THE ARGUMENT FOR RELATIONAL CONTENT}

The Master Argument does not on its own establish the Content Thesis. After all, it makes no claims about whether experience is fundamentally a matter of representing. On a weak reading of the Master Argument, it establishes only the Association Thesis. In order to establish the Content Thesis, we need an additional argument. One such additional argument is the Argument for Relational Content:

From $P \boldsymbol{I}$ and $\boldsymbol{P} 2$ : If a subject $S$ is perceptually related to her environment (while not suffering from blindsight or any other form of unconscious perception), then $S$ s environment sensorily seems a certain way to her.

P6: If a subject $S$ s environment sensorily seems a certain way to her, then $S$ is employing perceptual capacities that constitute the way her environment sensorily seems to her.

P7: If $S$ is employing perceptual capacities that constitute the way her environment sensorily seems to her, then $S$ is representing her environment in virtue of employing perceptual capacities.

P8: $S$ is representing her environment in virtue of employing perceptual capacities.

P9: If $S$ is representing her environment in virtue of employing perceptual capacities, then $S$ has a perceptual experience that is fundamentally a matter of representing her environment as being a certain way.

${ }^{14}$ It will be helpful to make two clarifications about the thesis that the way the environment seems to one determines accuracy conditions. First, there can be phenomenal differences between experiences that are not a matter of how the environment seems to one, but rather a matter of how one experiences. If I am shortsighted, my experience may be blurry, but I need not perceive the environment as being blurry. I have argued that perceptual content corresponds to the way the environment seems to the perceiver. This seems-content link is neutral on how those aspects of sensory character are accounted for that do not pertain to the way the environment seems to the perceiver. Second, the environment is arguably rarely and perhaps never the way it seems to us to be. We perceive plates to be round, although their shapes are much more complicated. We see surfaces to be colored, but it has been argued that surfaces do not have color properties. We see our environment to be populated by objects, but it has been argued that there really are no objects or at least not the kind of objects that we seem to see. In order to accommodate these phenomena, we need to loosen the notion of accuracy conditions in play or alternatively we need to accept widespread but explicable perceptual error. For a detailed discussion of this set of issues, see Pautz (2009) and Siegel (2010). If my argument for the thesis that experience has accuracy conditions holds, then it holds regardless of what stance one takes on this set of issues. 
Conclusion 3: $S$ has a perceptual experience that is fundamentally a matter of representing her environment as being a certain way. (from $P 8$ and $P 9$ )

P10: Perceptual capacities are by their nature linked to what they single out in the good case.

P11: If $S$ is representing her environment in virtue of employing perceptual capacities, then $S$ has a perceptual experience that is fundamentally a matter of being related to her environment in a certain way.

Conclusion 4: $S$ has a perceptual experience that is fundamentally a matter of being related to her environment in a certain way. (from $P 8$ and P11)

The basic idea in support of this argument is that when we perceive, we employ perceptual capacities by means of which we differentiate and single out particulars in our environment. The relevant particulars are external and mind-independent objects, events, property-instances, and instances of relations. Sensory seemings are understood as individuated by employing such perceptual capacities in a sensory mode, that is, modes such as seeing, hearing, touching, smelling, or tasting. Employing such perceptual capacities in turn constitutes a mental state with content.

Say we perceive a white cup on a desk. We employ our perceptual capacity to discriminate white from other colors and to single out white in our environment. Similarly we employ our capacity to differentiate and single out cup-shapes from, say, computer-shapes and lamp-shapes. It is not clear what it would be to single out an object in our environment without employing capacities of this kind. If this is right, then it is in virtue of employing such capacities that we are in a sensory state that is of a white cup.

Now how should we understand the capacities in play? They can be understood as conceptual capacities or as nonconceptual capacities. There are powerful reasons to understand perceptual content as nonconceptually structured. ${ }^{15}$ Therefore, I will focus on nonconceptual perceptual capacities. Indeed, I will focus on the cognitively most low-level nonconceptual perceptual capacities, namely, discriminatory, selective capacities. A discriminatory, selective capacity functions to differentiate and single out, where singling out a particular is a proto-conceptual analog of referring to a particular. ${ }^{16}$ So if we possess the discriminatory, selective capacity that functions to differentiate and single out red, we are in a position to differentiate instances of red from other colors in our environment and to single out instances of red. More generally, to possess a discriminatory, selective capacity is to be in a position to differentiate and single out the type of particulars that the capacity concerns, were one related to such a particular. So if we possess such a

${ }^{15}$ For discussion of nonconceptual content, see Peacocke (1998), Heck (2000), and Speaks (2005) For a recent defense of the idea that perceptual content is conceptually structured, see Glüer (2009) and Bengson et al. (2011).

${ }^{16}$ In some cases, a discriminatory capacity may also function to type the kind of particulars that the capacity concerns, but this is not an essential feature of the capacities in play. capacity, then - assuming no finking, masking, or other exotic case is involved (see Lewis 1997) - the following counterfactual should hold: If we were perceptually related to a particular that the capacity functions to single out, then we would be in a position to single out such a particular.

What happens in hallucination? Although such capacities are determined by functional connections between perceivers and their environment, arguably they can be employed even if one is misperceiving or hallucinating. After all, one could be prompted to employ the capacities due to nonstandard circumstances, such as unusual brain stimulation or misleading distal input. If this is right, then we can employ a perceptual capacity even if a relevant particular is not present-where a relevant particular is a particular of the type that the capacity functions to single out. The capacities employed account for the fact that in hallucinations we purport to single out particulars. Since in hallucination, we are not perceptually related to a particular, we fail to single out a particular in our environment. We merely purport to single out a particular. As a consequence, the capacities employed are baseless. They are baseless in the sense that the usual target of discrimination and selection-external, mind-independent particulars-are absent. Analogously, if we employ concepts, but fail to refer, the concepts employed remain empty. So if we hallucinate a white cup on a desk, we employ the capacity to discriminate and single out white from other colors and we employ the capacity to differentiate and single out cup-shapes from, say, computer-shapes and lamp-shapes. Since we are hallucinating rather than perceiving and so not perceptually related to a white cup, the capacities we employ are baseless. Yet even though we fail to single out any white cup, we are in a sensory state that is as of a white cup in virtue of employing the capacity to discriminate and single out white from other colors and cup-shapes from other shapes.

If this is right, then the very same perceptual capacity can be employed such that a particular is successfully singled out or employed without successfully singling out any particular. In this sense, employing perceptual capacities not only yields sensory seemings but moreover constitutes accuracy conditions. So employing perceptual capacities has all the hallmarks of content insofar as it yields something that is entertainable and that can be accurate or inaccurate. So if $S$ is employing perceptual capacities thereby constituting the way her environment sensorily seems to her, then $S$ is representing her environment in virtue of employing perceptual capacities. Indeed, insofar as employing perceptual capacities yields content and the employment of the perceptual capacities constitute the experience, the content is a proper part of experience rather than merely associated with the experience. If $S$ is representing her environment in virtue of employing perceptual capacities, then $S$ has a perceptual experience that is fundamentally a matter of representing her environment as being a certain way. So the subject bears the representation relation to the content rather than the mere association relation. As a consequence, the notion of content established by $P 6-P_{9}$ goes beyond that established by the Master Argument. Since $S$ is arbitrarily chosen, Conclusion 3 holds for 
any perceiver and so characterizes perceptual experience generally. Therefore, the Content Thesis follows from Conclusion 3. So by building on the Master Argument P6-P9 establish the Content Thesis.

In order to show why the idea that perceptual experience is a matter of employing perceptual capacities supports the view that experience is fundamentally not just representational but moreover relational, it is crucial to take a closer look at perceptual capacities. The function of perceptual capacities is to differentiate and single out the type of particulars that the capacity is of. It would be unclear what it would mean to possess a perceptual capacity, the very function of which is to single out a type of particular, without being in a position to single out such a particular when perceptually related to one. An example will help illustrate the point. If we possess the capacity to discriminate and single out white from other colors, we can use this capacity to single out white in our environment. Were we not in a position to use our capacity in this way, when perceptually related to an instance of white, we would not count as possessing the capacity. If this is right and perceptual content is yielded by employing such capacities, then relations to objects and property-instances are implicated in the very nature of perceptual content.

If the fact that perceptual capacities single out particulars in some situations but not in others has any semantic significance, then the content ensuing from employing these capacities will depend at least in part on the environment in which they are employed. After all, relations to particulars are implicated in the very nature of perceptual content, if perceptual content is yielded by employing perceptual capacities and such capacities function to single out particulars, then relations to particulars are a fundamental part of perceptual content. So insofar as the perceptual capacities that yield content function to single out particulars, perceptual experience is fundamentally both relational and representational. ${ }^{17}$

The notion of perceptual content in play can be specified more specifically as follows: Employing perceptual capacities yields a content type that subjectively indistinguishable experiences have in common. The token content ensues from employing perceptual capacities in a particular environment such that the token content co-varies with the environment of the experiencing subject. Since the perceptual capacities employed are the very same in subjectively indistinguishable experiences, such experiences have the same content type. Individuating experiences by a content type amounts to individuating experiences with regard to the experiencing subject's sensory state. In virtue of recognizing that perceptual experience is fundamentally both relational and representational, the suggested approach rejects all ways of factorizing perceptual content into internal and external components. ${ }^{18}$

${ }^{7}$ For an alternative way of avoiding the pitfalls of both austere representationalism and austere relationalism, see Dorsch (2013)

${ }^{18}$ For a detailed development of the semantic nature of such token contents, see my (2010). For a helpful discussion of the problems of factorizing mental content into internal and external components, see Williamson $(2000,2006)$. See also Burge (2010).
It is important to note that the content yielded by employing perceptual capacities need neither be conceptually nor propositionally structured. Indeed, the thesis that perceptual experience has content in virtue of experiencing subjects employing perceptual capacities allows for a substantive a way of understanding perceptual content as non-conceptual and non-propositional. Moreover, this thesis neither implies that the experiencing subject stand in a propositional attitude to the content of her experience nor does it rely on there being such a relation between the subject and content of an experience. So there is no need to say that the experiencing subject 'exes' that $p$-to use Byrne's (2009) phrase.

A further advantage of the suggested view is that it does not imply that experiences have an attributional structure, such as object $o$ is $F$. After all, the view does not depend on the idea that we are perceptually related to objects. It depends only on the idea that we are perceptually related to particulars. Those particulars need not be objects. They could be events or property-instances. So we may well be perceiving only property-instances and so not be attributing any property to a perceived object. Olfactory, gustatory, and tactile experiences may not have an attributional structure or at least not typically have such a structure. ${ }^{19}$ Since the suggested view neither implies nor presupposes that perception has an attributional structure, the view applies not just to visual and auditory experiences, but also olfactory, gustatory, and tactile experiences among other kinds of experiences.

Austere relationalism has it that for perceptual experience to ground perceptual knowledge of particular objects, there must be a phenomenal difference between experiences of qualitatively indistinguishable but numerically distinct objects. This is an unfortunate consequence of austere relationalism. On the view of content developed, we can avoid this unfortunate consequence. I have argued that the content of experience is in part dependent on the experiencer's environment. By arguing that only the part of the experience that is not environment-dependent grounds the sensory character of the experience, the provided view allows that experiences of numerically distinct but qualitatively indistinguishable objects differ in content, while having the same sensory character.

The view suggested is fundamentally representational, insofar as perceptual content is yielded by employing perceptual capacities and the employment of perceptual capacities constitute the experience. It is fundamentally relational insofar as a perception has the particular content it has because the experiencing subject is perceptually related to an environmental particular. Moreover, insofar as the content of experience is yielded by employing perceptual capacities the possession of which grounds the ability to single out objects and property-instances, relations to objects and property-instances are implicated in the very nature of experiential content

${ }^{19}$ For discussion, see Smith (2007), Batty (2010, 2011), and Fulkerson (2011). For discussions of whether auditory experiences have attributional structure, see Nudds (2001), O'Callaghan (2010), Ivanov (2011), Phillips (2013), and Matthen (forthcoming). See Macpherson (2011) for different ways of individuating the senses. 


\subsection{Rejoinder to Relationalist Response}

In his book Perception and its Objects, Brewer responds to my argument. His focus is on the first part of my Master Argument. He accepts the first two premises, but rejects the third premise of the argument. Recall that $P_{3}$ has it that if a subject's environment seems a certain way to her, then she has an experience with content $\mathrm{C}$, where $\mathrm{C}$ corresponds to the way her environment seems to her.

Brewer notes that the Master Argument can be understood in ways compatible with his view. As I have been careful to note, the Master Argument itself is compatible with just the Association Thesis. Accordingly, Brewer considers a strengthening of the Master Argument on which its conclusion is in genuine tension with his view. He does so by replacing my $P_{3}$ with a stronger thesis, that I will call $P_{3}{ }^{*}$.

P3*: "the idea of a person having an experience whose most fundamental nature is to be elucidated in terms of some kind of representational content C" $(2011$, p. 61).

My $P 6-P_{9}$ establish $P_{3}{ }^{*}$, so my Argument for Relational Content is built into $P_{3}{ }^{\star}$. Brewer rejects $P_{3}^{*}$ on the following grounds:

I simply deny that it follows from the fact that there are truths of the form 'o looks $F^{\prime}$ that apply to a person $S$ in virtue of her perceptual relation with $o$, that the most fundamental nature of that experience with the representational content (of some kind) that $o$ is F. On my interpretation of Schellenberg's Master Argument, this is the transition articulated explicitly by $\left[\mathrm{P3}^{*}\right]$. The account of looks offered in ch. 5 proves that $\left[P 3^{*}\right]$ is false on this interpretation. For I explain there precisely how various looks claims apply to $S$ in virtue of her perceptual relation with the world around her without assuming that the very nature of that perceptual relation is itself to be characterized in terms of any corresponding worldly representational content. The perceptual relation between perceivers and the mind-independent physical objects in the world around them is on that account more basic than any such representational contents and grounds the truth of the looks claims that perfectly reasonably inspire talk of perceptual representation $(2011$, p. 60).

In a nutshell, his objection to my argument is that the nature of the perceptual relation should not be understood as fundamentally involving representational content. On Brewer's view, the nature of perceptual experience is fundamentally only relational. ${ }^{20}$ Brewer does not consider the prospect that perceptual experience could be fundamentally both relational and representational. He seems to assume that these options are exclusive. One of my main points is that these options are

${ }^{20}$ Brewer focuses exclusively on the objects to which the perceiver is perceptually related, while I focus on the environment to which the perceiver is perceptually related. The environment contains objects, property-instances, relations, and events. This is a significant difference between Brewer's approach and my own. It can however be ignored for present purposes. not exclusive but complementary. I argue that perceptual experience is fundamentally both relational and representational. So Brewer and I agree that experience is fundamentally relational. What we disagree about is whether it is in addition fundamentally representational. ${ }^{21}$

Brewer's central argument against experience being fundamentally representational goes as follows:

If $S$ sees a mind-independent physical object $o$, then there are certainly (perhaps indefinitely) many true sentences of the form 'o looks F', but I would... deny that S's seeing o itself consists in the truth of those sentences or can be fruitfully illuminated by listing the facts that o looks F1, o looks $\mathrm{F} 2, \ldots, \mathrm{o}$ looks Fi, etc., or the fact that is visually seems to $\mathrm{S}$ that o is $\mathrm{F} 1$, o is $\mathrm{F} 2, \ldots, \mathrm{o}$ is $\mathrm{Fi}$, etc. S's seeing o, her perceptual experiential relation with that particular mind-independent physical object is more basic than any such facts and is what grounds the truth of all those sentences. (Brewer 2011, p. 62f.)

Brewer argues here that perceptual relations between a perceiver and an object are more basic than sentences expressing how the object looks to the perceiver. We can agree with Brewer that the truth of sentences is derivative of their truthmakers. So we can agree with him that "S's seeing $o$, her perceptual experiential relation with that particular mind-independent physical object is more basic than any such facts and is what grounds the truth of all those sentences," where these sentences express how the environment looks to a person. However, what is at issue in the debate on whether experience has content is not the relation between sentences and their truthmakers. The thesis that experience is fundamentally a matter of representing the environment is neither a thesis about sentences nor a thesis about sentential truth. It is a thesis about mental content. No one thinks that perception is fundamentally a matter of sentences that express how the object looks to perceivers being true. ${ }^{22}$

While everyone can accept that perception is not fundamentally a matter of such sentences being true, there is an argument in close vicinity of Brewer's argument that strengthens his case against representationalism. This argument has the same form as Brewer's argument and preserves the intuitions guiding his argument, but is about mental content rather than sentences:

If $S$ sees a mind-independent physical object $o$, then there are certainly (perhaps indefinitely) many accurate mental contents of the form 'o looks $F$, but $S$ 's

${ }^{21}$ I would also quibble with Brewer's wording when he characterizes representationalism as endorsing the thesis that "the very nature of that perceptual relation is itself to be characterized in terms of any corresponding worldly representational content" $(2011, \mathrm{p}$. 60). I would not say that the perceptual relation can be understood in terms of representational content, but only that perceptual experience-rather than the perceptual relation-can be understood (at least in part) in terms of representational content

${ }^{22}$ For a discussion of the relation between mental content and linguistic meaning, see Speaks
(2006). On perceptual reports, see Brogard (forthcoming). 
seeing $o$ itself does not consist in the accuracy of those mental contents or can be fruitfully illuminated by listing the facts that $o$ looks $F 1$, o looks $F_{2}, \ldots$, o looks $F i$, etc., or the fact that it visually seems to $S$ that $o$ is $F_{1}, o$ is $F_{2}, \ldots, o$ is $F i$, etc. $S$ 's seeing $o$, her perceptual experiential relation with that particular mind-independent physical object is more basic than any such facts and is what grounds the accuracy of all those mental contents.

In response to this rephrased version of Brewer's argument, we can say that we can accept that $S$ seeing $o$ is more basic than the accuracy of the mental content. However, we can accept this without accepting that $S$ seeing $o$ is more basic than the fact that $S$ has an experience, which is fundamentally a matter of representing $o$. So we can accept that $S$ seeing $o$ is more basic than the accuracy of the mental content, while acknowledging that $S$ seeing $o$ is not more basic than $S$ representing $o$. I argue that $S$ being perceptually related to $o$ and $S$ representing $o$ are equally fundamental.

A further central reason for Brewer to reject representationalism is that according to him representationalism cannot account for illusions. Brewer focuses on the Müller-Lyer illusion, an illusion prompted by two lines that in fact have the same length, but that seem to have different lengths due to outward looking hashes on one line and inward looking hashes on the other line. He discusses several ways a representationalist could analyze what the content of such an illusion could be (2011, pp. 65-69). For the sake of argument, I will assume that the ways of accounting for illusions in a representationalist framework that Brewer considers do not work for the very reasons that Brewer cites. Rather than take issue with Brewer's arguments, I will put forward a way that a representationalist could account for illusions that Brewer does not consider.

First, consider perceiving a cup at an angle. One way of analyzing what we represent when we perceive a cup at an angle is that we represent the shape of the cup in two ways: <the cup has shape', the cup has shape" $>$. The single primed property is an intrinsic property and the double primed property is a situation-dependent property, that is, it is a property that is determined by one's location and the intrinsic shape of the cup. More specifically, a situation-dependent property is a (nonconstant) function of an intrinsic property and one or more situational features, that is, features of the environment that determine how objects are presented such as the lighting conditions and the subject's location in relation to perceived objects. This means that fixing the intrinsic properties of an object and the situational features fixes the situation-dependent properties. Furthermore, situation-dependent properties are ontologically dependent on and exclusively sensitive to intrinsic properties and situational features. I understand the intrinsic properties, of say a white cup, to include among other properties, the shape and size of the cup. More generally, intrinsic properties of an object are the properties that an object has regardless of the situational features. They are the properties that an object has that do not depend on the object's relations to other individuals distinct from itself. ${ }^{23}$

${ }^{23}$ For a development of the notion of situation-dependent properties, see my (2008). For a critical
While the single and double primed properties are different kinds of properties, a perceiving subject need not represent these metaphysical facts. The perceiving subject may just represent that the cup has a certain shape in one respect and a different shape in another respect. So perception need not represent the metaphysical basis of the distinction between shape' and shape". For perceptual content to be consistent, it is sufficient that a distinction is represented. It is not necessary that it is represented what the metaphysical basis for that distinction is.

Now consider the Müller-Lyer illusion. One could say that the two lines that prompt the Müller-Lyer illusion have the same length in one respect and have different lengths in another respect. So one can distinguish two conceptions of length: Call these lengths' and lengths". In light of this distinction, we can say that when we are perceptually related to the two lines, we represent $<\mathrm{A}$ and $\mathrm{B}$ have the same lengths', A and B have different lengths $s^{\prime \prime}>$. The primes mark that one distinguishes between different respects. Due to the primes, the content of our experience is not inconsistent. In the case of the Müller-Lyer illusion, the sense in which the lines look different in length cannot in any straightforward way be analyzed in terms of situation-dependent properties. After all, there is no situational feature in the environment in virtue of which the lines look different in length. However, the way in which we represent the difference between intrinsic and situation-dependent properties can be exploited for an analysis of how we represent the lines. As in the case of seeing the cup, we can say that the single and double primed properties lengths' and lengths" are different kinds of properties, but that a perceiving subject need not represent these metaphysical facts. For perceptual content to be consistent, it is sufficient that a distinction is represented. If this is right, then we have no reason to reject that experience is fundamentally a matter of representing one's environment to account for illusions. So again, we have no reason to reject the Content Thesis.

\section{References}

Batty, C. (2010). A representational account of olfactory experience. Canadian Journal of Philosophy, 40, 511-538.

Batty, C. (2011). Smelling lessons. Philosophical Studies, 153, 161-174.

Bengson, J., Grube, E., \& Korman, D. (2011). A new framework for conceptualism. Noûs, $45,167-189$.

Brewer, B. (2006). Perception and content. European Journal of Philosophy, 14, 165-181.

Brewer, B. (2007). Perception and its object. Philosophical Studies, 132, 87-97.

Brewer, B. (2011). Perception and its Objects. Oxford: Oxford University Press.

Brogaard, B. (forthcoming). Perceptual reports. In M. Matthen (Ed.), Oxford Handbook of the Philosophy of Perception. Oxford: Oxford University Press.

Bronner, B., Kerr, A., \& Ganson, T. (forthcoming). Burge's defense of perceptual content. Philosophy and Phenomenological Research.

Burge, T. (2010). Origins of Objectivity. Oxford: Oxford University Press.

Byrne, A. (2001). Intentionalism defended. The Philosophical Review, 110, 199-240. 
Byrne, A. (2009). Experience and content. Philosophical Quarterly, 59, 429-451. Campbell, J. (2002). Reference and Consciousness. Oxford: Oxford University Press.

Campbell, J. (2010). Demonstrative reference: The relational view of experience and the proximality principle. In R. Jeshion (Ed.), New Essays on Singular Thought (pp. 193212). Oxford: Oxford University Press.

Chisholm, R. (1957). Perceiving: A Philosophical Study. Ithaca, NY: Cornell University Press. Crane, T. (2009). Is perception a propositional attitude? Philosophical Quarterly, 59, $452-469$.

Davies, M. (1992). Perceptual content and local supervenience. Proceedings of the Aristotelian Society, 92, 21-45.

Dorsch, F. (2013). Experience and introspection. In F. Macpherson \& D. Platchias (Eds.) Hallucination (pp. 69-165). Cambridge, MA: MIT Press.

Fish, W. (2009). Perception, Hallucination, and Illusion. New York: Oxford University Press. Fulkerson, M. (2011). The unity of haptic touch. Philosophical Psychology, 24, 493-516.

Genone, J. (forthcoming). Appearance and illusion. Mind.

Glüer, K. (2009). In defence of a doxastic account of experience. Mind and Language, 24, 297-327.

Gupta, A. (2012). An account of conscious experience. Analytic Philosophy, 53, 1-29.

Heck, R. (2000). Nonconceptual content and the space of reasons. The Philosophical Review, 109, 483-523.

Ivanov, I. (2011). Pains and sounds. Journal of Consciousness Studies, 18, 143-163.

Jackson, F. (1977). Perception. Cambridge: Cambridge University Press.

Jagnow, R. (2012). Representationalism and the perspectival character of perceptual experience. Philosophical Studies, 157, 227-249.

Johnston, M. (2004). The obscure object of hallucination. Philosophical Studies, 120, 113-183.

Johnston, M. (2006). Better than mere knowledge? The function of sensory awareness. In T. Gendler \& J. Hawthorne (Eds.), Perceptual Experience (pp. 260-290). Oxford: Oxford University Press.

Lewis, D. (1997). Finkish Dispositions. Philosophical Quarterly, 47, 143-158.

Lycan, W. G. (1996). Consciousness and Experience. Cambridge, MA: MIT Press.

Macpherson, F. (2011). Individuating the senses. In F. Macpherson (Ed.), The Senses: Classical and Contemporary Readings (pp. 3-46). Oxford: Oxford University Press.

Madary, M. (2012). Anticipation and variation in visual content. Philosophical Studies, 165 , $335-347$.

Martin, M. G. F. (2002a). The transparency of experience. Mind and Language, 17, 376-425. Martin, M. G. F. (2002b). Particular thoughts and singular thoughts. In A. O'Hear (Ed.), Logic, Thought and Language (pp. 173-214). Cambridge: Cambridge University Press.

Martin, M. G. F. (2004). The limits of self-awareness. Philosophical Studies, 103, 37-89.

Matthen, M. (forthcoming). On the diversity of auditory objects. Review of Philosophy and Psychology.

McGinn, C. (1982). The Character of Mind. Oxford: Oxford University Press.

Nanay, B. (forthcoming). The representationalism versus relationalism debate: Explanatory contextualism about perception. European Journal of Philosophy.

Nudds, M. (2001). Experiencing the production of sounds. European Journal of Philosophy, 9, 210-229.

O'Callaghan, C. (2010). Sounds: A Philosophical Theory. Oxford: Oxford University Press.
Pautz, A. (2009). What are the contents of experiences? Philosophical Quarterly, 59, 483-507. Pautz, A. (2010). Why explain visual experience in terms of content? In B. Nanay (Ed.) Perceiving the World (pp. 254-310). Oxford: Oxford University Press.

Peacocke, C. (1998). Nonconceptual content defended. Philosophy and Phenomenological Research, $63,381-388$.

Phillips, I. (2013). Hearing and hallucinating silence. In F. Macpherson \& D. Platchias (Eds.), Hallucination (pp. 333-360). Cambridge, MA: MIT Press.

Raleigh, T. (forthcoming). Phenomenology without representation. European Journal of Philosophy.

Russell, B. (1913). Theory of Knowledge. London: Routledge.

Schellenberg, S. (2008). The situation-dependency of perception. Journal of Philosophy, 105, 55-84.

Schellenberg, S. (2010). The particularity and phenomenology of perceptual experience. Philosophical Studies, 149, 19-48.

Schellenberg, S. (2011). Perceptual content defended. Nô̂s, 45, 714-750.

Schellenberg, S. (2013). Experience and Evidence. Mind, 487, 699-747.

Siegel, S. (2010). Do experiences have content? In B. Nanay (Ed.), Perceiving the World (pp. 333-368). Oxford: Oxford University Press.

Smith, B. (2007). The objectivity of taste and tasting. In B. Smith (Ed.), Questions of Taste: The Philosophy of Wine (pp. 41-77). Oxford: Oxford University Press.

Speaks, J. (2005). Is there a problem about nonconceptual content? Philosophical Review, $114,359-398$.

Speaks, J. (2006). Is mental content prior to linguistic meaning? Noûs, 40, 428-467.

Travis, C. (2004). Silence of the senses. Mind, 113, 57-94.

Tye, M. (1995). Ten Problems of Consciousness. Cambridge, MA: MIT Press.

Williamson, T. (2000). Knowledge and Its Limits. Oxford: Oxford University Press.

Williamson, T. (2006). Can cognition be factorized into internal and external components?

In R. Stainton (Ed.), Contemporary Debates in Cognitive Science (pp. 291-306). Oxford: Blackwell.

Wu, W. (forthcoming). Against division: Consciousness, information, and visual stream. Mind and Language. 